\title{
Selenium, glutathione and glutathione peroxidases in blood of patients with chronic liver diseases ${ }^{\star}$
}

\author{
Jolanta Czuczejko ${ }^{1 凶}$, Bronisław A. Zachara ${ }^{1}$, Ewa Staubach-Topczewska ${ }^{2}$, \\ Waldemar Halota ${ }^{2}$ and Józef Kędziora ${ }^{1}$ \\ ${ }^{1}$ Department of Biochemistry, and ${ }^{2}$ Department of Infectious Diseases, The Ludwik Rydygier \\ Medical University in Bydgoszcz, Poland
}

Received: 24 September, 2003; revised: 27 November, 2003; accepted: 09 December, 2003

Key words: chronic liver disease, glutathione, glutathione peroxidase, oxidative stress, selenium

\begin{abstract}
Disturbances in the antioxidant system could play a role in pathogenesis of chronic liver disease. The aim of our study was to evaluate the levels/activities of antioxidants in blood of patients with chronic liver disease.

We estimated selenium and glutathione concentrations and glutathione peroxidase activities in blood of 59 patients with chronic hepatitis B or C virus infection (group 1) and 64 patients with alcoholic, autoimmune or cryptogenic chronic liver disease (group 2). The results were compared with $\mathbf{5 0}$ healthy controls.

Whole blood and plasma selenium and red cell glutathione concentrations were significantly lower in the patients compared with the controls. Red cell glutathione peroxidase activity was slightly reduced in both subgroups of group 1 and in group 2 with normal alanine aminotransferase values. Plasma glutathione peroxidase activity was slightly but significantly higher in patients with elevated aminotransferase values.

The findings suggest that disturbances in antioxidant parameters in blood of patients with chronic liver disease may be the cause of the peroxidative damage of cells.
\end{abstract}

Metabolism of various endo- and exogenous compounds and viruses generate reactive oxygen species (ROS) which are involved in the pathogenesis of liver diseases (Clot et al., 1994; Buljevac et al., 1996; Oh et al., 1997). ROS rap- idly react with a variety of molecules and thereby interfere with cellular function (Inoue, 1994). Cells are equipped with nonenzymatic and enzymatic protective systems that play an important role in the scavenging of free radi-

\footnotetext{
This work was financed by a grant from The Ludwik Rydygier Medical University in Bydgoszcz (BW 36/98).

${ }^{\otimes}$ Address for correspondence: Jolanta Czuczejko, Department of Biochemistry, The Ludwik Rydygier Medical University, 85-092 Bydgoszcz, Poland; phone: (48 52) 585 3755; fax: (40 52) 585 3753, e-mail: joczu@esculap.pl
}

Abbreviations: ALT, alanine aminotransferase; GSH-Px, glutathione peroxidase; GSH, reduced glutathione; HBV, hepatitis B virus; HCV, hepatitis $\mathrm{C}$ virus; ROS, reactive oxygen species. 
cals. Among the antioxidative enzymes are glutathione peroxidases (GSH-Pxs) which catalyze the breakdown of inorganic and organic peroxides (Rayman, 2000). In this way GSH-Pxs prevent lipid peroxidation and thus protect the cell membranes from oxidative damage. Reduced glutathione (GSH) functions as an antioxidant in several ways, as a substrate for GSH-Px and glutathione $S$-transferase (GST) as well as a direct antioxidant, independent of the enzymes protecting the cell membranes from oxidative damage (Moron et al., 1979).

GSH-Pxs are the most extensively characterized selenoproteins. Selenium serves its antioxidative purpose through the GSH-Pxs. Four different GSH-Pxs are known: cellular or cytosolic or classical (GSH-Px 1), gastrointestinal (GSH-Px 2), plasma or extracellular (GSH-Px 3) and phospholipid hydroperoxide (GSH-Px 4) (Burk \& Hill, 1999). Cellular and plasma GSH-Pxs are used as the functional parameters the assessment of selenium (Se) status (Holben \& Smith, 1999).

In plasma Se is incorporated (as selenocysteine) also into selenoprotein $\mathrm{P}$, and bound (as selenomethionine) to albumin (Deagen et al., 1993; Xia et al., 2000). The liver is the main organ in the metabolism and homeostasis of selenium in the human body (Buljevac et al., 1996; Whanger, 1998), because these selenoproteins are predominantly synthesized and secreted by the liver (Deagen et al., 1993; Behne \& Kyriakopoulos, 2001). The clinical importance of Se in liver diseases emerged from experimental studies in animals, where Se deficiency was shown to induce liver necrosis (Schwarz \& Foltz, 1957). A significantly lower Se content has been observed in the liver tissue on autopsy of patients who had died from cirrhosis of the liver, compared with healthy subjects (Dworkin et al., 1984; Zachara, 2001). Cirrhosis of the liver is most commonly caused by long-lasting alcohol abuse or infection with hepatitis B (HBV) and C virus (HCV) (Buljevac et al., 1996). Several groups have reported that excessive alcohol consumption is associated with lowered Se concentrations in blood components (Girre et al., 1990; Dworkin et al., 1984; Tanner et al., 1986). Loguercio et al. (1997) have shown that Se concentration in whole blood and plasma of patients with HCV-related chronic liver disease was significantly lower, independently of their nutritional status (well-nourished or malnourished cirrhosis), than in healthy controls.

Our present study was undertaken in order to investigate the Se and GSH concentrations as well as GSH-Pxs activities in blood of patients with chronic liver diseases of different etiology.

\section{MATERIALS AND METHODS}

The patients with chronic liver disease ( $\mathrm{n}=$ 123) from the Department of Infectious Diseases, Medical University in Bydgoszcz, aged 17-85 years (mean, 53 years) participated in the study. Liver injury of patients was proven by histological and laboratory examinations. Venous blood samples were drawn, after overnight fasting, into tubes containing lithium heparin (Vacuette, Greiner Labortechnik, Kremsmunster, Austria). The blood samples were divided into two portions, one of which was used for measurements of hematocrit value, hemoglobin, selenium and glutathione concentrations. The second part was centrifuged $(2500 \times$ $\mathrm{g}, 4^{\circ} \mathrm{C}, 10 \mathrm{~min}$ ) and the plasma was stored at $-80^{\circ} \mathrm{C}$ and was used for further investigations. The buffy coat was removed and the red blood cells were washed two times in an excess of chilled physiological saline solution. The washed red blood cells were then hemolyzed in distilled water (1:4, v/v) and by freezing and thawing. The hemolysate was centrifuged $\left(22000 \times \mathbf{g}, 4^{\circ} \mathrm{C}, 60 \mathrm{~min}\right)$, and the supernatant was used for GSH-Px activity and hemoglobin (routine cyanmethemoglobin method) concentration measurements.

The patients $(\mathrm{n}=123)$ were divided into two groups according to etiology of disease: group 1 comprised 59 patients (aged 24-85 years; mean 54 years) with chronic hepatitis B $(\mathrm{n}=32), \mathrm{C}(\mathrm{n}$ $=23)$ or $\mathrm{B}$ and $\mathrm{C}$ virus infection $(\mathrm{n}=4)$, and group 2 included 64 patients (aged 17-83 years; 
mean 52 years) diagnosed as alcoholic liver injury $(n=50)$, autoimmune $(n=3)$ or cryptogenic $(n=11)$ chronic liver disease. Additionally, each group of patients was divided into two subgroups, depending of the plasma alanine aminotransferase (ALT) activity: subgroups 1A and $2 \mathrm{~A}$ with ALT activity below $40 \mathrm{U} / \mathrm{l}(\mathrm{n}=23$ and $\mathrm{n}=26$, respectively), and $1 \mathrm{~B}$ and $2 \mathrm{~B}$ with ALT activity above $40 \mathrm{U} / \mathrm{l}(\mathrm{n}=36$ and $\mathrm{n}=38$ subjects, respectively). The third group was composed of 50 healthy subjects aged 24-65 years (mean 42 years) and were recruited from the same area as the patients. All participants (healthy subjects) attending the study gave written consent, and the study protocol was approved by the University Ethics Committee for Medical Research (No. 10/97).

Se determination in whole blood and plasma was performed by the fluorometric method of Watkinson (1966) with 2,3-diaminonaphthalene (DAN) as the complexing reagent. The 4,5-benzpiazselenol formed in the reaction of Se with DAN was quantitatively extracted with cyclohexane. Fluorescence measurements were made using a Hitachi F-4010 spectrofluorometer (Tokyo, Japan). The accuracy of the method was checked in whole blood and serum (batches 205052 and 311089, respectively) reference materials (Seronorm, Nycomed, Oslo, Norway). The levels of Se found in the reference whole blood was $81.7 \pm 2.5 \mathrm{ng} / \mathrm{ml}$ and in serum $84.5 \pm 2.4 \mathrm{ng} / \mathrm{ml}$, while the certified was 83 and $86 \pm 1.09 \mathrm{ng} / \mathrm{ml}$, respectively.

GSH-Px activity in red cell hemolysates and plasma was measured by the coupled method of Paglia and Valentine (1967) with tert-butyl hydroperoxide as substrate. The reaction was carried out at $25^{\circ} \mathrm{C}$ in a spectrophotometer fitted with a constant temperature cell housing (Hewlett Packard No. 8453, Vienna, Austria). Enzyme activity was expressed as units (U) per $\mathrm{g} \mathrm{Hb}$ or $\mathrm{U}$ per liter of plasma. One $\mathrm{U}$ of the enzyme activity was expressed as $1 \mu \mathrm{mol}$ of NADPH oxidized per minute. The details of the Se and GSH-Px determinations are described elsewhere (Iwanier \& Zachara, 1995). GSH concentration in the blood was assayed by the colorimetric method of Beutler (1971) with 5',5'-dithio-bis-2 (nitrobenzoic acid) as a complexing reagent and the results were expressed as mmol per liter of red cells. ALT activity measurement was carried out in a clinical laboratory using a commercially available kit produced by Roche (normal values < $40 \mathrm{U} / \mathrm{l}$ ).

All statistical analyses, including the calculations of mean \pm S.D., the Student's $t$-test, and the simple linear regression analysis were carried out using Microsoft Excell and Statistica software. The Pearson correlation test was used when appropriate. Significance was set at $P<$ 0.05 level.

\section{RESULTS}

\section{Selenium and glutathione concentrations in blood}

The Se concentration in whole blood and in plasma (Table 1) of patients of group 1 and 2 was, irrespective of ALT activity, highly significantly lower $(P<0.0001)$ than in the control group. In the subgroups with normal ALT activity (group $1 \mathrm{~A}$ and $2 \mathrm{~A}$ ) the Se concentrations in blood and plasma were significantly lower than in the subgroups with higher ALT activity. In both groups of patients the red cell GSH concentration was significantly lower compared with healthy controls (Table 2). In subgroup 1B the GSH concentration was also significantly lower compared with subgroup 1A. In group 2 lowered GSH concentrations were similar in both subgroups.

\section{Red cell and plasma glutathione peroxidase activities}

Red cell GSH-Px activity in group 1 was significantly lower than in controls only in the patients with elevated ALT activity (Table 2). By contrast, in group 2 the activity of the red cell enzyme was significantly lower in the patients with normal ALT values and did not differ in the patients with elevated ALT activity when 
compared with the control group. The mean plasma GSH-Px activities (Table 2) in subgroups $1 \mathrm{~A}$ and $2 \mathrm{~A}$ were lower compared with the controls, while in subgroups $1 \mathrm{~B}$ and $2 \mathrm{~B}$ the

\section{DISCUSSION}

In our study diminished concentrations of Se in whole blood and plasma were observed both

Table 1. Selenium concentration $(\mathrm{ng} / \mathrm{ml})$ in whole blood and in plasma of patients with chronic liver disease.

\begin{tabular}{|c|c|c|c|c|c|}
\hline group 1 & \multicolumn{2}{|l|}{ Whole blood } & \multicolumn{3}{|c|}{ Plasma } \\
\hline $\begin{array}{l}\text { Control } \\
\text { group }\end{array}$ & $\begin{array}{c}\mathrm{A} \\
\mathrm{ALT} \leq 40 \mathrm{U} / 1\end{array}$ & $\begin{array}{c}\mathrm{B} \\
\mathrm{ALT}>40 \mathrm{U} / 1\end{array}$ & $\begin{array}{l}\text { Control } \\
\text { group }\end{array}$ & $\begin{array}{c}\mathrm{A} \\
\mathrm{ALT} \leq 40 \mathrm{U} / 1\end{array}$ & $\begin{array}{c}\mathrm{B} \\
\mathrm{ALT}>40 \mathrm{U} / 1\end{array}$ \\
\hline $89.5 \pm 15.6$ & $\begin{array}{l}58.6 \pm 13.3 \\
P<0.0001^{*}\end{array}$ & $\begin{array}{l}74.3 \pm 15.0 \\
P<0.0001^{*}\end{array}$ & $67.4 \pm 11.7$ & $\begin{array}{l}43.6 \pm 12.1 \\
P<0.0001^{*}\end{array}$ & $\begin{array}{l}53.7 \pm 11.6 \\
P<0.0001^{*}\end{array}$ \\
\hline & \multicolumn{2}{|c|}{$P<0.001^{* *}$} & & \multicolumn{2}{|c|}{$P<0.002^{* *}$} \\
\hline group 2 & \multicolumn{2}{|l|}{ Whole blood } & \multicolumn{3}{|c|}{ Plasma } \\
\hline $\begin{array}{l}\text { Control } \\
\text { group }\end{array}$ & $\begin{array}{c}\mathrm{A} \\
\mathrm{ALT} \leq 40 \mathrm{U} / 1\end{array}$ & $\begin{array}{c}\mathrm{B} \\
\mathrm{ALT}>40 \mathrm{U} / 1\end{array}$ & $\begin{array}{l}\text { Control } \\
\text { group }\end{array}$ & $\begin{array}{c}\mathrm{A} \\
\mathrm{ALT} \leq 40 \mathrm{U} / 1\end{array}$ & $\begin{array}{c}\mathrm{B} \\
\mathrm{ALT}>40 \mathrm{U} / 1\end{array}$ \\
\hline $89.5 \pm 15.6$ & $\begin{array}{l}52.5 \pm 15.7 \\
P<0.0001^{*}\end{array}$ & $\begin{array}{l}64.4 \pm 17.5 \\
P<0.0001^{*}\end{array}$ & $67.4 \pm 11.7$ & $\begin{array}{l}37.4 \pm 11.6 \\
P<0.0001^{*}\end{array}$ & $\begin{array}{l}48.7 \pm 15.0 \\
P<0.0001^{*}\end{array}$ \\
\hline & \multicolumn{2}{|c|}{$P<0.006^{* *}$} & & \multicolumn{2}{|c|}{$P<0.002^{* *}$} \\
\hline
\end{tabular}

Differences statistically significant compared with: *controls; **between subgroups

activities were significantly higher than in the controls. In both subgroups with elevated ALT the plasma GSH-Px activities were significantly higher compared with the subgroups having normal ALT.

Positive, significant correlations were noted between red cell GSH-Px activity and red cell GSH concentration in the patients, when group 1 and 2, with normal ALT values, were combined ( $\mathrm{r}=0.620 ; P<0.0001$; Fig. $1 \mathrm{~A})$, and in the subgroups with elevated ALT activity $(\mathrm{r}=0.340$; $P<0.0001$; Fig. 1B). A highly significant correlation ( $\mathrm{r}=0.480, P<0.0001$ ) was also observed when all the patients were taken together. A strong correlation was found between red cell GSH-Px activity and whole blood Se concentration ( $\mathrm{r}=0.535$; $P<0.0001$ ) (Fig. $2 \mathrm{~A}$ ) as well as between plasma GSH-Px activity and plasma Se concentration ( $\mathrm{r}=0.626 ; P<0.0001)$ (Fig. 2B) when both groups with normal ALT activity were combined. In the groups with elevated ALT no correlation exists between these two parameters. in patients with viral hepatitis (group 1) as well as in alcoholics, autoimmune and cryptogenic chronic liver disease patients (group 2). Several groups have shown that in alcoholics Se concentrations in plasma (Dworkin et al., 1984; 1985; Johansson et al., 1986; Girre et al., 1990; Buljevac et al., 1996; Burk et al., 1998; Guarini et al., 1998; Loguercio et al., 1997), whole blood (Dworkin et al., 1984; 1985, Johansson et al., 1986; Girre et al., 1990; Loguercio et al., 1997) and in red cells (Dworkin et al., 1984; 1985) are significantly lower compared with healthy controls. Johansson et al. (1986) have demonstrated that in whole blood and plasma of patients with alcoholic liver cirrhosis Se concentration is significantly lower than in healthy subjects. They have also shown that in male alcoholics without liver cirrhosis, with at least 1 month of abstinence before the study, plasma Se level did not differ from the controls.

In our study, in patients of group 2 both with normal and elevated ALT activities (78\% of this group were alcoholics), the Se concentrations in 
whole blood and plasma were lower by 9.3 to $14.1 \%$ compared with group 1. Guarrini et al. (1998) reported that in patients with liver cirrhosis Se concentration was significantly re- cies are frequent in such patients. It is well established that the main source of dietary Se is protein and lower protein intake may be the major cause of the reduced Se concentration in

Table 2. Glutathione concentration in red cells ( $\mathrm{mmol} / \mathrm{l})$ and glutathione peroxidase activity in red cells $(\mathrm{U} / \mathrm{g} \mathbf{H b})$ and in plasma $(\mathrm{U} / \mathrm{l})$ of patients with chronic liver disease.

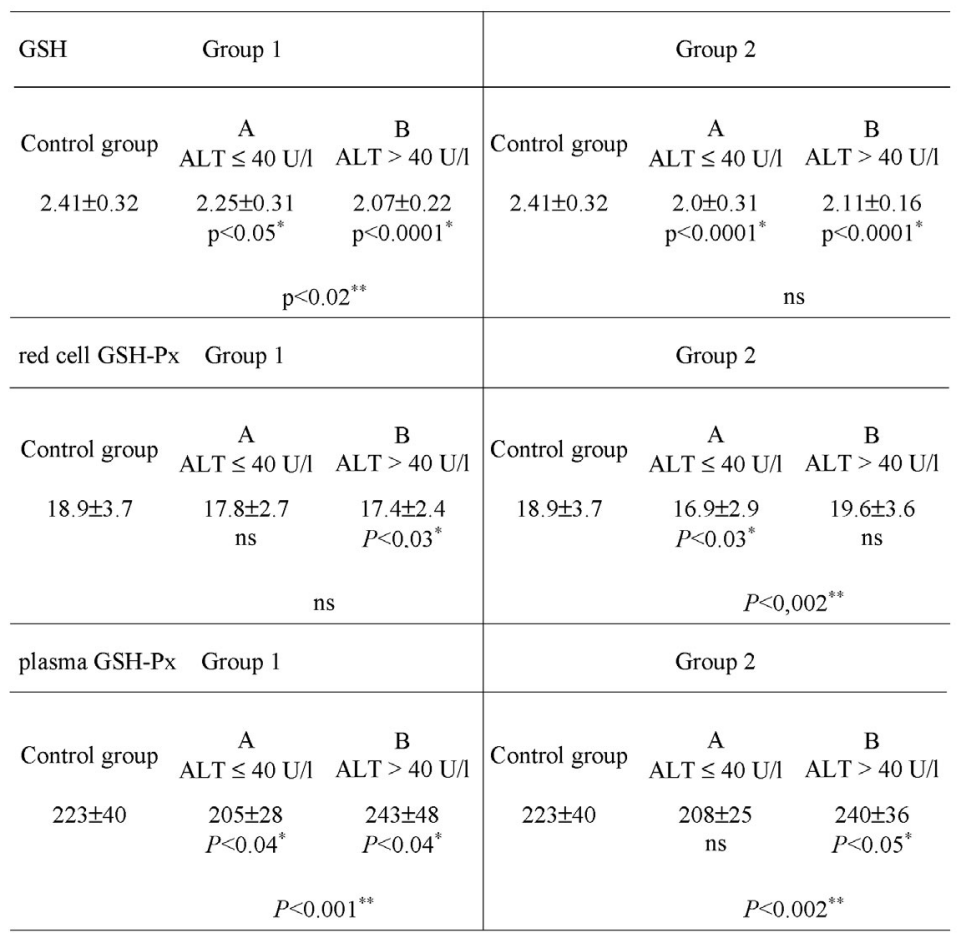

Differences statistically significant compared with: *controls; **between subgroups; ns, not significantly

duced but - in contrast to our data - the lower serum Se level was similar in both alcoholic and viral liver cirrhosis. When both subgroups of our patients with chronic hepatitis $\mathrm{B}$ and $\mathrm{C}$ were combined, the Se concentration in whole blood and plasma was lower by 24 and $26 \%$, respectively, when compared with healthy subjects. Considerably reduced Se levels in whole blood and plasma of HCV patients were reported by Loguercio et al. (1997); the values were lower by $42 \%$ and $24 \%$, respectively, compared with controls.

For alcohol liver disease Dworkin et al. (1984; 1985) have suggested several possibilities of lowered Se level, such as nutritional deficiencies, diminished absorption, alcohol-induced alteration of Se metabolism, abnormal losses in urine or feces and others. Nutritional deficien- blood components (Burk et al., 1998). Precise nutritional assessment performed in patients with alcoholic liver disease revealed a good correlation $(r=0.91)$ between serum concentration of Se and nutritional status (Tanner et al., 1986). Burk et al. (1998) have recently documented that in patients with liver cirrhosis, being the consequence of hepatitis virus B or/and C infection, alcohol consumption, autoimmune, cryptogenic and others, plasma Se and selenoprotein $\mathrm{P}$ concentrations were lower compared with controls. These parameters declined in proportion to the severity of the cirrhotic condition. This indicates that hepatic injury impairs the hepatic synthesis of selenoproteins and selenium containing proteins (albumin), thus contributing to low plasma selenium concentration. Cirrhosis impairs also the transsulfuration 

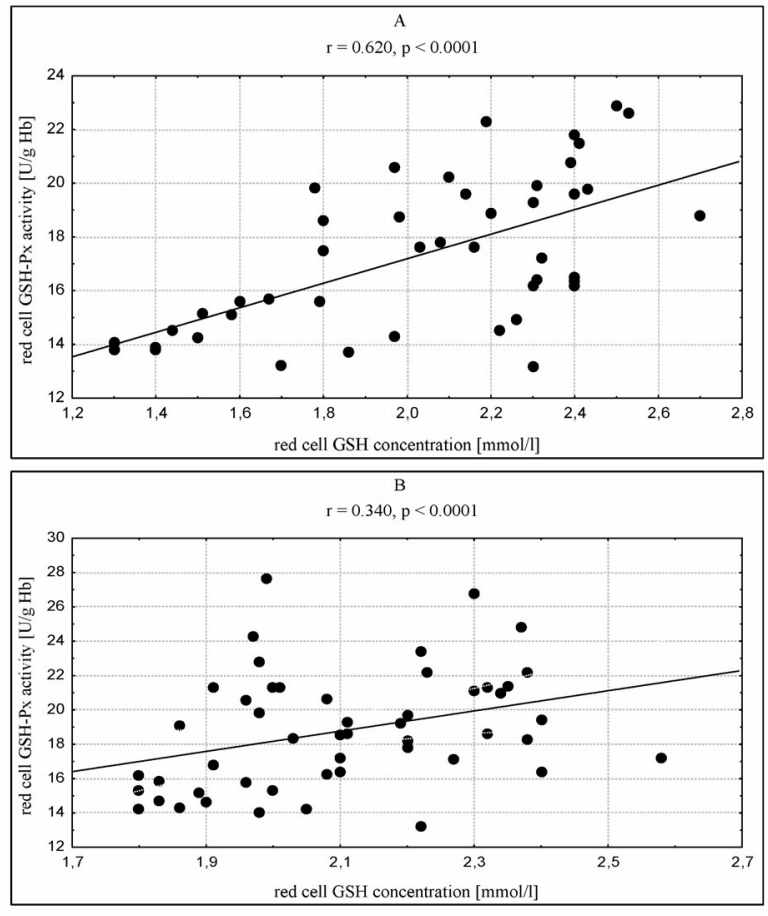

Figure 1. Relationship between red blood cell GSH-Px activity and GSH concentration in patients with chronic liver disease of group 1 and 2 with normal ALT activities (A) and with elevated ALT values (B).

pathway which is necesary to make Se (from selenomethionine) available for selenoprotein synthesis (Burk et al., 1998).

Small (lower or higher), nonsignificant differences in red cell GSH-Px activity between liver cirrhosis and alcoholic liver disease compared with healthy controls have been reported (Johansson et al., 1986; Tanner et al., 1986; Akkus et al., 1997). In the same way, in our study red cell GSH-Px activity in patients of group 1 with normal ALT values and in group 2 with elevated ALT activity was the same as in the control group. In the other two subgroups the GSH-Px activity was slightly, but significantly lower than in healthy subjects. Girre et al. (1990) studied red cell and plasma GSH-Px activity in heavy drinkers with chronic alcohol disease without liver cirrhosis and found that both enzymes were significantly lower than in the controls. Johansson et al. (1986) have reported that in patients with liver cirrhosis and alcoholic liver disease the activity of plasma
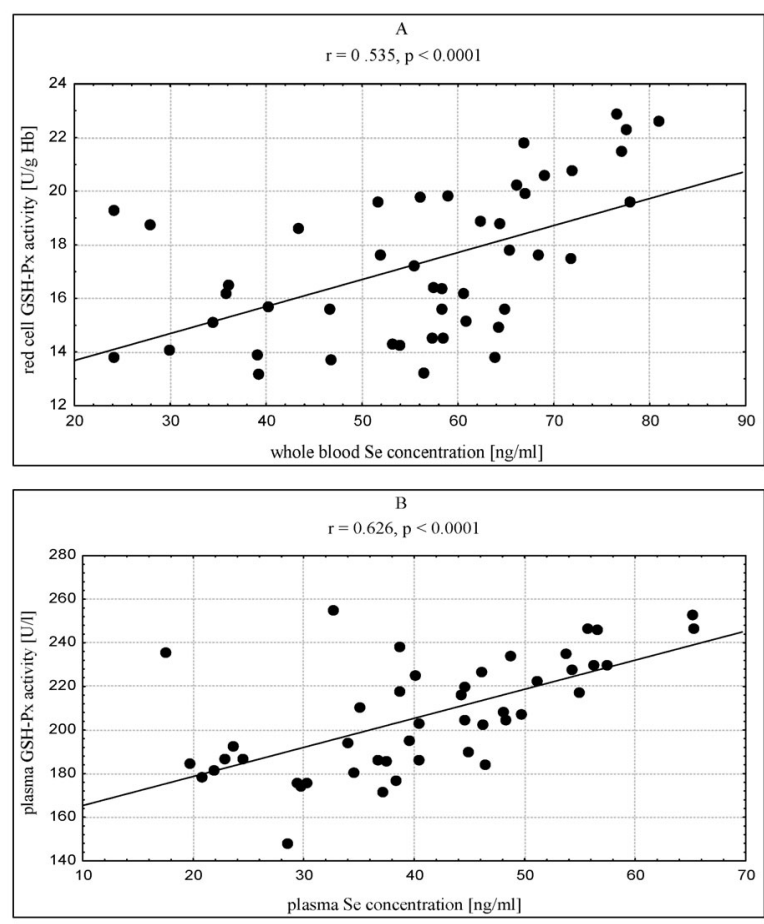

Figure 2. Relationship between red blood cell GSH-Px activity and Se concentration in whole blood in patients with chronic liver disease of group 1 and 2 with normal ALT activity (A), and between plasma GSH-Px activity and plasma Se concentration in patients of both groups with normal ALT values (B).

GSH-Px is unchanged. Guemouri et al. (1993) observed that in chronic alcoholics, with no clinical or biological evidence of cirrhosis, plasma GSH-Px activity was slightly (non significantly) elevated compared with controls. Our study shows that in patients with normal ALT values (when patients of both subgroups are combined) plasma GSH-Px activity is slightly but significantly $(P<0.02)$ reduced, while in the subgroups with elevated ALT values this activity is slightly but significantly $(P<0.03)$ higher. Burk et al. (1998) showed that plasma GSH-Px activity in patients with Child class A (according to the Child-Pugh classification) of liver cirrhosis was almost the same as in healthy subjects but it increased in proportion to the severity of the disease. The cause of such contradictory results may be release of the intracellular isoforms of the enzyme from the injured liver. Injury of the liver does not exert an influence 
on plasma GSH-Px, because this enzyme originates primarily from proximal tubular cells of the kidney (Avissar et al., 1994; Burk et al., 1998). However, the decreased activity of both plasma and red cell selenoenzymes may be caused by decreased Se concentration in blood.

Over $90 \%$ of GSH inflow in systemic circulation is accounted for by the influx of this peptide from the liver (Bianchi et al., 1997). Swiętek and Juszczyk (1997) have shown that red cell GSH concentration in patients with acute or chronic viral hepatitis A, B and C is significantly reduced. Similarly reduced blood GSH levels have been reported for patients with liver disease of both alcoholic and non-alcoholic etiology (Clot et al., 1994; Grattagliano et al., 1996; Bianchi et al., 1997; Świętek \& Juszczyk, 1997). Our study is in accord with the above mentioned results and shows that GSH concentration in red cells of patients with chronic liver disease, of both viral and other etiology, is significantly lower than in healthy subjects. The primary cause accounting for the decreased blood GSH level in patients with liver diseases is a decreased production in and decreased inflow from the liver (Grattagliano et al., 1996; Bianchi et al., 1997).

Positive and highly significant correlations between GSH and GSH-Px in red cells as well as between GSH-Px activities and Se concentrations were observed. Such a good correlation between these parameters may mean that with most patients red cell GSH-Px activity is well corelated with GSH and Se accessibility.

In conclusion, our results show that patients with chronic liver disease have lower Se and GSH concentrations in blood components. Red cell GSH-Px activity in patients shows a tendency to lower values compared with healthy controls. Plasma GSH-Px activity is reduced in patients with normal ALT values but is increased in those with elevated ALT. The decreased Se concentration may results from hepatic injury and dysfunction of this organ. These findings may indicate that disturbances in antioxidant levels/activities may facilitate ROS production which, in turn, could play a role in the pathogenesis of chronic liver diseases.

\section{REFER ENCES}

Akkus I, Gültekin F, Aköz M, Cağlayan O, Bahcaci S, Gülsüm C, Ay M, Gürel A. (1997) Effect of moderate alcohol intake on lipid peroxidation in plasma, erythrocyte and leukocyte and on some antioxidant enzymes. Clin Chim Acta.; 266: 141-7.

Avissar N, Ornt DB, Yagil Y, Horowitz S, Watkins RH, Kerl EA. (1994) Human kidney proximal tubules are the main source of plasma glutathione peroxidase. Am $J$ Physiol.; 255: 367-75.

Behne D, Kyriakopoulos A. (2001) Mammalian selenium-containing proteins. Annu Rev Nutr.; 21: 453-73.

Beutler E. (1971) Red cell metabolism. In A manual of biochemical methods. Beutler E, ed, pp 11-2. Grune-Stratton, New York.

Bianchi G, Bugianesi E, Ronchi M, Fabbri A, Zoli M, Marchesini G. (1997) Glutathione kinetics in normal man and in patients with liver cirrhosis. J Hepatol.; 26: 606-13.

Buljevac M, Romić Ź, Vucelić B, Banić M, Krznarić Ż, Pleško S. (1996) Serum selenium concentration in patients with liver cirrhosis and hepatocellular carcinoma. Acta Med Croatica; 50: 11-4.

Burk RF, Early DS, Hill KE, Palmer IS, Boeglin ME. (1998) Plasma selenium in patients with cirrhosis. Hepatology.; 27: 794-8.

Burk RF, Hill KE. (1999) Orphan selenoproteins. BioEssays.; 21: 231-7.

Clot P, Tabone M, Arico S, Albano E. (1994) Monitoring oxidative damage in patients with liver cirrhosis and different daily alcohol intake. Gut.; 35: 1637-43.

Deagan JT, Butler JA, Zachara BA, Whanger PD. (1993) Determination of the distribution of selenium between glutathione peroxidase, selenoprotein $\mathrm{P}$, and albumin in plasma. Anal Biochem.; 208: 176-81. 
Dworkin BM, Rosenthal WS, Gordon GG, Jankowski RH. (1984) Diminished blood selenium levels in alcoholics. Alcoh Clin Exp Res.; 8: $535-8$.

Dworkin B, Rosenthal WS, Jankowski RH, Gordon GG, Haldea D. (1985) Low blood selenium levels in alcoholics with and without advanced liver disease. Correlations with clinical and nutritional status. Digest Dis Sci.; 30: 838-44.

Girre C, Hispard E, Therond P, Guedj S, Bourdon R, Dally S. (1990) Effect of abstinence from alcohol on the depression of glutathione peroxidase activity and selenium and vitamin E levels in chronic alcoholic patients. Alcohol Clin Exp Res.; 14: 909-12.

Grattagliano I, Vendemiale G, Sabba C, Buonamico P, Altomare E. (1996) Oxidation of circulating proteins in alcoholics: role of acetaldehyde and xantine oxidase. $J$ Hepatol.; 24: 28-36.

Guarini P, Stanzial AM, Olivieri O, Casaril M, Galvani S, Pantalena M, Corrocher R. (1998) Erythrocyte membrane lipids and serum selenium in post-viral and alcoholic cirrhosis. Clin Chim Acta.; 270: 139-50.

Guemouri L, Lecomte E, Herbeth B, Pirollet P, Paille F, Siest G, Artur Y. (1993) Blood activities of antioxidant enzymes in alcoholics before and after withdrawal. $J$ Stud Alcohol.; 54: 626-9.

Holben DH, Smith AM. (1999) The diverse role of selenium within selenoproteins. A review. J Am Diet Assoc.; 99: 836-43.

Inoue M. (1994) Protective mechanism against reactive oxygen species. In The liver: biology and pathobiology. Arias IM, Boyer JL, Fausto N, Jacoby WB, Schachter DA, Shafritz DA, eds, pp 443-59. Raven Press Ltd, New York.

Johansson U, Johnsson F, Joelsson B, Berglund M, Akesson B. (1986) Selenium status in patients with liver cirrhosis and alcoholism. Brit J Nutr.; 55: 227-33.

Loguercio C, De Girolamo V, Federico A, Feng SL, Cataldi V, Del Vecchio Blanco C, Gialanella G. (1997) Trace elements and chronic liver diseases. J Trace Elem Med Biol.; 11: 158-61.
Moron MS, Depierre JW, Mannervik B. (1979) Levels of glutathione, glutathione reductase and glutathione S-transferase activities in rat lung and liver. Biochim Biophys Acta.; 582: 67-78.

Oh SI, Kim CI, Chun HJ, Lee MS, Park SC. (1997) Glutathione recycling is attenuated by acute ethanol feeding in rat liver. $J$ Kor Med Sci.; 12: 316-21.

Paglia DE, Valentine WN. (1967) Studies on the quantitative and qualitative characterization of erythrocyte glutathione peroxidase. J Lab Clin Med.; 70: 158-69.

Rayman MP. (2000) The importance of selenium to human health. Lancet.; 356: 233-41.

Schwarz K, Foltz CM. (1957) Selenium as an integral part of factor 3 against dietary necrotic liver degeneration. J Am Chem Soc.; 79: $3292-3$.

Świętek K, Juszczyk J. (1997) Reduced glutathione concentration in erythrocytes of patients with acute and chronic viral hepatitis. J Viral Hepatitis.; 4: 139-41.

Tanner AR, Bantock I, Hinks L, Lloyd B, Turner NR, Wright R. (1986) Depressed selenium and vitamin $\mathrm{E}$ levels in an alcoholic population. Possible relationship to hepatic injury through increased lipid peroxidation. Dig Dis Sci.; 31: 1307-12.

Watkinson JH. (1966) Fluorometric determination of selenium in biological material with 2,3-diaminonaphthalene. Anal Chem.; 38: 92-7.

Whanger PD. (1998) Metabolism of selenium in humans. J Trace Elem Exp Med.; 11: 227-40.

Xia Y, Ha P, Hill K, Butler J, Whanger P. (2000) Distribution of selenium between fractions in erythrocytes, plasma, hair, and fingernails of Chinese women living in selenium-deficient, -adequate, and -excessive areas of China. J Trace Elem Exp Med.; 13: $333-42$.

Zachara BA, Pawluk H, Bloch-Bogusławska E, Śliwka KM, Korenkiewicz J, Skok Ź, Ryć K. (2001) Tissue level, distribution, and total body selenium content in healthy humans and in some diseases in Poland. Arch Environ Health.; 56: 461-6. 